LA W RENCE LIVERMORE N A TIONAL LABORATORY
High Energy Repetition-Rate Average-Power Laser Driver (HERALD) for the Dynamic Compression Sector (DCS) at the Advanced Photon Source (APS)

A. Bayramian

June 18, 2013 
This document was prepared as an account of work sponsored by an agency of the United States government. Neither the United States government nor Lawrence Livermore National Security, LLC, nor any of their employees makes any warranty, expressed or implied, or assumes any legal liability or responsibility for the accuracy, completeness, or usefulness of any information, apparatus, product, or process disclosed, or represents that its use would not infringe privately owned rights. Reference herein to any specific commercial product, process, or service by trade name, trademark, manufacturer, or otherwise does not necessarily constitute or imply its endorsement, recommendation, or favoring by the United States government or Lawrence Livermore National Security, LLC. The views and opinions of authors expressed herein do not necessarily state or reflect those of the United States government or Lawrence Livermore National Security, LLC, and shall not be used for advertising or product endorsement purposes.

This work performed under the auspices of the U.S. Department of Energy by Lawrence Livermore National Laboratory under Contract DE-AC52-07NA27344. 


\section{High Energy Repetition-Rate Average-Power Laser Driver (HERALD) for the Dynamic Compression Sector (DCS) at the Advanced Photon Source (APS)}

The DCS facility at the APS is a partnership between APS and Washington State University dedicated to dynamic compression research. The DCS represents an important capability supporting NNSA's scientific mission by offering pursuit of fundamental science that has not been possible at any synchrotron radiation facility in the past. The DCS will focus on time-resolved X-ray diffraction and imaging measurements in materials subjected to dynamic compression. By providing in-situ time-resolved measurements at microscopic length scales, DCS will enable a fundamental understanding of the mechanisms governing a broad range of time-dependent, condensed matter phenomena under dynamic loading such as structural transformations, inelastic deformation, fracture, and chemical reactions. Such measurements are essential for validating multi-scale modeling of the materials phenomena under shock wave and shockless compression. The energies (hard X-rays) and the time-structure (ns-separated pulses) of the APS X-rays are uniquely suited to examine timedependent changes in materials subjected to a broad range of peak stresses $(\sim 0.05$ Mbar to $>1$ Mbar $)$ and timedurations (10-500 ns). Creating the shocks in materials can be accomplished with a variety of sources including gas guns and laser based drivers. The requirements of a laser based solution are summarized by fig. 3 which indicates that a $100 \mathrm{~J}$ class beam could generate up to $10 \mathrm{Mbar}$ shocks in $>100$ micon radius spot size, and with $\mathrm{kJ}$ class laser systems more than 100 Mbar would be attainable with similar spot sizes.

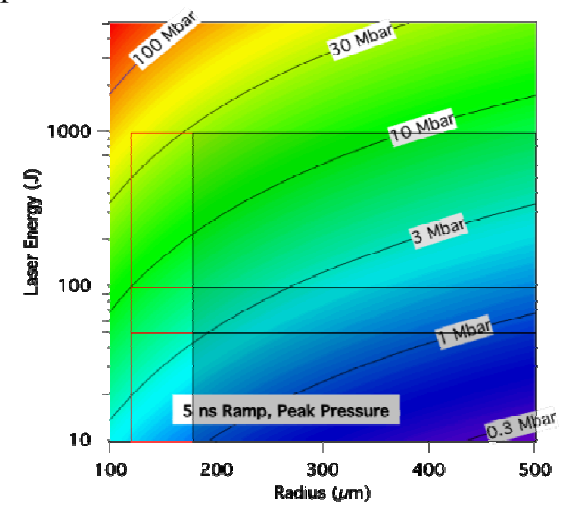

Fig. 1 Shock pressure capability plot as a function of laser energy and beam radius

Coincidently LLNL has been developing high energy lasers for over five decades, and more recently diode pumped high average power lasers culminating in the Mercury laser system demonstration (60 J @ 1 w, $10 \mathrm{~Hz}, 15 \mathrm{~ns})$. This work was followed by benchmarked designs for a laser iInertial fusion energy laser driver(8.1kJ @ 1w,6 kJ @ $3 \mathrm{w}, 16 \mathrm{~Hz}, 5-15 \mathrm{~ns}$ ) as well as scaled versions for near term commercial applications (200 J @ 1w, 160 J @ 2w, 10 Hz, 5-20 ns). Systems at the $100 \mathrm{~J}$ class are large enough to provide interesting data for the DCS while remaining price competitive with traditional flashlamp based systems. LLNL high energy diode pumped systems offer the following benefits:

- High repetition rate $(>10 \mathrm{~Hz})$

- Reliability / long lifetime

- Lower cost/shot (capital + operational)

- Higher efficiency ( 10X) vs flashlamp systems

- Scalability to $\sim 10 \mathrm{~kJ}$ class

- Large industrial base

- Scientific and industrial community are vectoring to diode pumped systems worldwide

Currently there are no commercial solutions to this specification. The combination of diode pumped laser systems from LLNL and APS-DCS could provide a marriage of two areas in which the US is the recognized world leader, thereby producing a world-leading capability for material science. LLNL is poised to build and deliver a $200 \mathrm{~J}$ class laser system for an external sponsor. Execution of this project will greatly reduce cost, risk, and nonrecurring engineering associated with this scale of laser system. A $100 \mathrm{~J}$ class system (Fig.2) could be provided to DCS with high confidence within 1-2 years after the external sponsor system is complete (end 2015). The 100-J class system would provide the following output characteristics according to the table below:

\begin{tabular}{|c|c|}
\hline Characteristic & Specification \\
\hline Energy (J) & 100 \\
\hline Wavelength (nm) & 526 \\
\hline Repetition rate $(\mathrm{Hz})$ & 10 \\
\hline Pulsewidth (ns) & $2-20$ \\
\hline Pulse shape & arbitrary shaping \\
\hline Output Beam size $\left(\mathrm{cm}^{2}\right)$ & $3.6 \times 3.6$ \\
\hline Beam profile & Flat top \\
\hline Energy stability (rms) & $<1 \%$ \\
\hline Beam contrast (Peak/Ave) & $<1.1$ \\
\hline Target beam size/shape & $>100 \mu \mathrm{m} /$ flat top \\
\hline Footprint & $\sim 5 ' \times 16^{\prime}$ \\
\hline
\end{tabular}

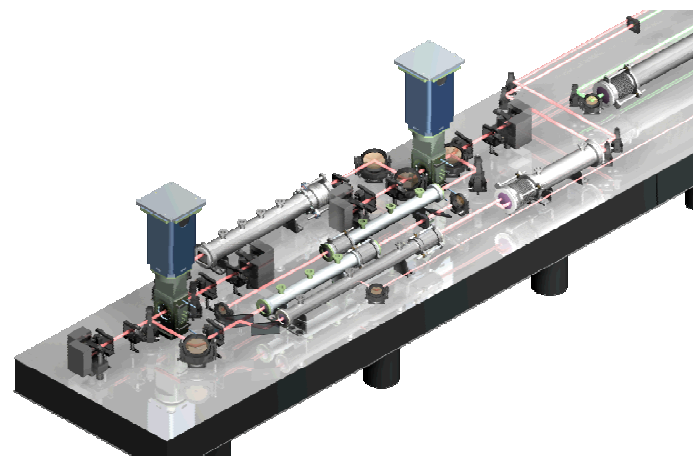

Fig. 2 CAD model picture of the HERALD laser system 